\title{
Structural changes in tourism market that highlight the product specialization of travel intermediaries
}

\author{
IRIS MIHAJLOVIĆ \\ Department of Economics and Business Economics \\ University of Dubrovnik \\ Lapadska obala 7 \\ 20000 Dubrovnik \\ CROATIA
}

\begin{abstract}
Changes in society and the economy have a strong impact on specialization in tourism. The impact of structural changes in tourism, on the level of specialization of business of travel intermediaries, was analyzed in this paper. The impact of social changes intensifies the need for potential transformation of the role and the postion of travel intermediaries. In order to quantify this impact, the results of a survey conducted on a sample of tourists who stayed in the destination of Dubrovnik were used.This primary research was related to the sample of (400) respondents . In this paper structural changes in the tourism market are shown in results of the direction of specialization of programs of products according to market requests, area of vertical integrations, and an area of characteristics of package tours. Thus, contribution is made in an important area of the necessities for specialization of services in tourism. The results showed that the attitudes of tourists about the importance of the health and recreation program statistically significantly affect the specialization of the program of travel agencies. Considering vertical integrations findings show that : a) modality of booking services via travel agencies statistically significantly increases the likelihood of choosing of the specialized program of the travel agency ; b) also, the booking via Internet statistically significantly increases the likelihood of choosing the specialized program of the package tours. The results of this paper point to the need for constant adaptation to the requirements of tourists, where the reason for the adjustment could be found in a way of doing business based on internal and external changes in the environment.These changes include changes in tourist's style of living, specific attitudes towards reasons for travel, leisure and the way of communication using innovative tools when booking their services. Thus, the role of travel intermediaries is reviewed and examined by varibles that define their future market position.
\end{abstract}

Key-Words: structural changes, travel agencies, specialization, tourism, product, managers

Received: December 26, 2019. Revised: May 29, 2020. Re-revised: June 3, 2020. Accepted: June 4, 2020. Published: June 5, 2020

\section{Introduction}

Different approaches to the intensity of problem related to different industry or sector should take into account the emphasize on new technologies that could have a major impact on savings in the field of automation and increases the complementary role of employee work in labour intense sector, which increases efficiency and delivers optimal solutions. Also reallocation of resources in accordance with structural changes in demand that offer necessity of unified procurement policy with a coordinated distribution of supplies to places that need it most would lead to more efficient outcomes- restoring normal logistics requires not only close coordination between different departments but also effective cooperation between regions on macro aspect. The travel industry is a service industry in which individuals or corporations sell travel related products to the public, including accommodation, catering, transportation, and sightseeing [1] The travel industry not only shares the characteristics of the service industry, but also serves as an intermediary in the tourism industry. As social economic and environmental changes impact tourism, transformation of issues of concept of sustainability from idealism to realism, considered by uncontrolled dynamics of environmental effects is highlighted Changes in structure of leisure time, social values, and the economic market, the deepening globalization and advances in high technology increased the income of the public worldwide. As an assumption of competitiveness, numerous motives and dynamics of its changes make pressure on tourism supply towards in specialisation of services/products [2] Human 
Development Index (HDI) - is an indicator that testifies to their authenticity and value in the moment of existing social sensitivity and questioning of health stability such in unpredicted conditions delegated by uncertain market conditions in 2020. Explained as a summary measure of average achievement in key dimensions of human development in shape of a long and healthy life, being knowledgeable and having a decent standard of living, HDI is supposed to present the base and reflex of possible coexistence of tourism system with other areas of human activities moving chosen priorities by independent model of individuals towards areas that guarntee succes and an excellence. The rise in income stimulates their consuming power and boosts their need for special form of tourism. Travel providers must consider diverse and specialized tourism production that meets expectations through the optimal quality of services in accordance of customer preferences toward products. is common In conditions of economic growth, for purpose of future diversification, specialisation in tourism is focused on gathering intelligence on tourism markets. Using the services based on the excitement, new experiences, and specialization in the tourism industry contribute to the creating of differences between mass tourism and the tourism system which completely meets the specific needs of tourists [3]. Negative consequences about mass tourism in present circumstances, it is important to analyze the impact of socio-environmental and economic factors on the strategic oriented activities on companies in tourism [4].In the travel industry, the travel providers are looking for partners in the face of the highly competitive tourism market. Under such a delicate cooperative relationship, the travel providers' understanding of its positions and roles in the industrial network point out strategic approach. In parallel, they find solutions to formulate and implement appropriate business model. Specialization is concerned with human labour, although it may include other factors of production process. Studies on tourism and smart specialisation have only emerged recently in the context of tourism sustainable development .Based on acquiring of the knowledge in some specific field it is also focused on education to the production of certain products. The assumption is that limiting to narrower fields of activities increases the speed, skills and consequently the labour productivity, especially as regards the activities which consist a high concentration of human labour as a factor of production, such as in the service activities. Hence, the specialization in tourism refers to activities based on the narrow assortment of goods and services that achieves a better control of the market . The diversification as a development strategy is applied in situation when are in an existing the business and on existing market rates of growth are limited or do not meet the interests of capital. Studies on tourism and smart specialisation have only emerged recently in the context sustainable economic growth and resilience [5]. [6].. Regions specialising in tourism may be characterised by opportunities for regional development based on natural and cultural resources, which might not be sustainably managed. This could result in a vicious circle in which regional amenities attract visitors, which in turn contribute to their damage [7]. The original attractiveness of destinations often falls into the background under the influence of uncertainties as global threats.

\section{Literature review on specialization process of travel intermediaries in terms of dynamic changes}

Coexisting with other sectors is a necessity in order to stimulate development while an emphasis refers to partnerships. Once market conditions stabilized, the time to regain a sense of security that is a precondition for the existence of the labour intensive sector should reconsider as well as holistic approach to the system to tourism. It is important to find out in details explained way of industry linkages that would met benefits in an optimal model of partnerships. Incentives should facilitate the coexistence of industries that can give impetus to the economy. The globalization process is supported by technological changes. Information technology has a strong impact on tourism trends by creating, distributing and informing about tourism products. There is sufficient evidence that globalization on the tourist market manifested through a quantitative increase in the market of tourist demand, but at the same time acts as a catalyst for further strong structural changes of the same market. According to many authors, globalization is supported by dynamics of information and communication technologies. ICT contributes to spatial-temporal convergence. In order to ensure availability of services to all, considering the current dislocation of users, it is needed an additional grant for customization of eservices and e-contents. Tourism sector missing the support of contemporary infrastructure, thus 
cutting the possibility access to includes digital information; thereby Croatia lags behind the EU average. An additional problem is the lack of entrepreneurial skills. Considering education spending, it is close to the EU average. In 2017, Croatia spent $4.7 \%$ of its GDP on education (the EU average is $4.6 \%$ ). As a proportion of general government expenditure, the investment in education was $(10.5 \%)$ is also close to the EU average $(10.2 \%)$. The share of spending on tertiary education is $21.5 \%$, above the EU average of $15.0 \%$. In 2017 , the percentage of $16-74$ year-olds who have reported having basic or above-basic overall digital skills was the second lowest in the EU (41\%, as compared with an EU average of $57 \%$ ). The proportion of people regularly using the internet is among the lowest in the EU (73\%, as compared with the EU average of $83 \%$ ). The digital skills of young people aged 16-19 are slightly better than EU average, but they dropped significantly between (70\%) in 2016 and (59\%) in 2017 [8]. Croatia takes the position of "a moderate innovator" considering the share of companies involved in innovations which is below the average of EU. The establishment of innovative companies should support the improvement of business through innovation potentials and their commercialization through the activities of existing SMEs, particularly in areas of tourism. Despite the trend of service providers to bypass travel and tourism intermediaries by selling their services directly to consumers, ICT has definitely new role as a tool that influences the efficiency of placement of services of travel intermediaries. New challenges for intermediaries are influenced by new trends in consumer behaviour and new ICT solutions. A successful purchase of travel packages through the Internet towards research is very possible if people use the Internet very often backwards for four years and more, resulting in confidence among tourists and travel agents. Also, tourists who found travel through the Internet spend more in the destination compared to those using some other way agents [9]. The reason is that it allows tourists to interact with travel agents and gives them the ability to adapt purchased services to their own needs. Fast data transfer over the Internet, reduces time spent in communication between operators and tourists is reduced. To the satisfaction of tourists and their behaviour is greatly influenced by the reaction of travel agents on their on-line query [10].. Internet is an efficient innovative tool. Due to technological changes, globalization is supported and enabled.. Information technology has a strong impact on tourism trends by creating, distributing and informing about tourism products. Competitiveness is no longer a local issue, so most companies operate in a global competitive environment. World economy is showing intense changes, so it is becoming increasingly difficult to penetrate the world market without strong links with multinational companies and regional economic integrations. According to Eurostat (2019), under the title Tourism Industries Employment, in 2010, there were 77,000 travel agency and tour operator enterprises in Europe that between them generated EUR 300 billion in turnover, and in 2015 there were 104,919 travel agencies (NACE class N7911), and tour operators (NACE class N7912) [11]. Package holidays (packages) accounted for about half of this amount. This equals over $40 \%$ of the total international tourism receipts recorded in 2017 worldwide. Europeans depend on the services of travel intermediaries, despite the trend of service providers to bypass travel and tourism intermediaries by selling their services directly to consumers. Based on the very short official data time series available, it can be noted that the variation of the number of tour operators and travel agencies in the EU, is not showing a specific trend over the period 2012 to 2014; slightly declining from 2011 to 2012, and increasing afterwards from 2012 to 2014, Figure 1.

Figure 1: Number of tour operators and travel agencies in European Union, EU-28, composition 2018 Eurostat,

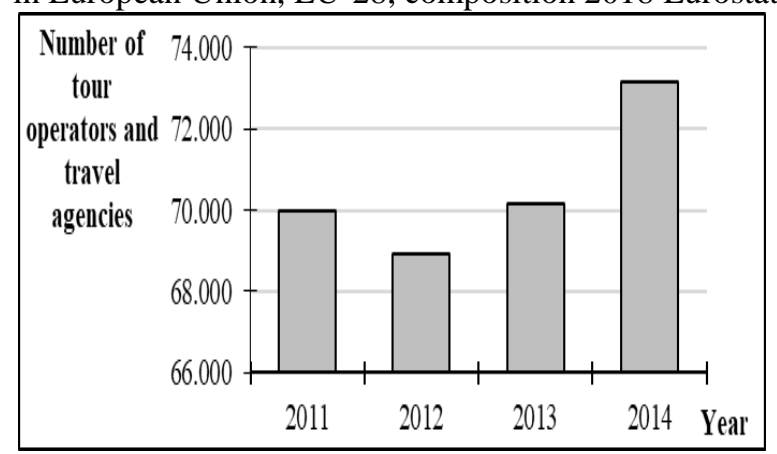

Source: Authors' creation

According to the Figure 1, in the observed period the number of tour operators and travel agencies in European Union was the lowest in $2012(68,909)$ whereas the largest number of tour operators and travel agencies in European Union was achieved in $2014(73,159)$. There was no available data for the European Union as whole for other periods. Looking at the dynamics of tour operators over the countries in 2010 and 2016, according to the data availability, different directions are recognized. 
Countries with different number of inhabitants, are shown different rates of change directions, regardless the economics of digital development level. The countries with large number of inhabitants, such as Germany and Italy, Spain, all being highly developed old EU countries, but also Poland, performed similarly, showing an increasing number of tour operators in 2016 regarding 2010. However, small countries regarding their number of inhabitants, Croatia, Hungary, as transition countries, Cyprus, Malta, Switzerland and Luxembourg, as more developed ones, are showing a decreasing tendency in 2016 towards 2010. So, the largest relative increase in period from 2010 to 2016 achieved the Netherlands (57.0\%) and Portugal (48.5\%) whereas the largest relative decrease in the observed period had Malta (-24.0\%) and Cyprus ($18.6 \%$ ) [12]. New technologies, as an indicator of changing living conditions, but also a catalyst for globalization, have a great impact on tourism trends, and thus on the role of intermediaries. It is also considered interesting to analyze consistently different numbers of tour operators and travel agencies. An effort for clarification of indicators that impact the number of tour operators and travel agencies should be pointed out, with a purpose to help policy creators in the tourism industry to improve the travellers 'and other customers' needs, as well as to improve the satisfaction of the owners of the respective enterprises by an income increase, respectively. Under innovations, the evolution of the relational structure between organizations, and their interactions in a network diagram that results with high intertwine should be considered. Key concepts referring to service marketing include: relationships, interaction, network creation and quality The Internet booking of travel and holiday accommodation improves accessibility to different tourism contents in a country. In that way, it has positive impacts on the further development of tourism. Emerging of special interests of the tourism demand make pressure on tourism supply towards specialization of travel providers and travel agencies. Future intermediation in the tourism distribution channel will be pointed by organizational reengineering of processes, changes in communication visible through the increasing of online bookings. Principals will develop Internet-based interfaces with consumers to improve customer satisfaction, remaining loyal to traditional market segments and targeting on specific market niches. Due the innovation process, travel intermediaries are able to renew their offer at increasingly shorter periods.
The innovation process refers to improve the agency's image and to achieve customer loyalty. The need for travel agencies and tour operators (which must have a profound knowledge of their clients' motivations, expectations and particularly of their needs) intertwines on every segment of the tourism market and with any ,new product” is prominent. Regarding the diversification of packages in order to encourage the customer interest and to realize turnover, ensuring the growth of companies - travel intermediaries try to adapt the development of diverse range of tourism products, according to the diverse needs of market segments.. To overcome the non-storability and seasonality in tourist demands of the service industry, travel intermediaries integrate two oposite and totaly different travel market poles. While travel market competition was fierce and the needed market space was expanding, the channels intergation is imposed as one-way option that united sometimes-different interests of key players. Travel industry integrates and makes full use of resources and diversifies the development channels to increase the market demand. Moreover, travel providers, and intemediaries cooperate in placement (online booking, promotion,distribution) of customized packages. Combining their social and economic roles travel intermediaries and providers united efforsts in actitivites towards local tourism resources, by an organization with joint sales, centralized operations and sharing benefits formed for different travel market niches. Creativity generally manifests itself in an extensive manner and implies that travel intermediaries anticipate customers' needs and wants and identify new destinations. Specialising in one or a few colocated products contributes to the shaping of a coherent destination image, friendly environment condition suported by expertise and shapes identitiy, reducing barriers and encourages economies of scale and thematic linkages. Each of the agents providing the interdependent services that make up a complex tourism product (e.g. accommodation, food, transport, leisure - and, in the case of balneotherapy tourism, treatment and specific procedures) adds a certain value to the final product.. It is the more necessary to ensure a clear delimitation of the processes, activities and resources undertaken by tourism organisations.

The value of the tourism product is defined, controlled and permanently adapted to consumers' needs and especially to their desires. Bearing in mind the rapid structural changes of tourist demand, among the participants, in the 
competitive tourism market, an important place will belong to those SMEs that are skilled, professional and intuitive, that would be able use the knowledge taking the advantages of trends as the specific chances of the environment and to adapt them in accordance with their possibilities to successful placement of products.One of the accepted possibilities seems the implementation of the strategy of specialization and diversification in business of travel agencies. Accordingly, the strategic advantage of travel agencies is based on experiences, monitoring of specific market requirements and adapting the products to special interest groups. As services are defined as changeable, non-storable, indivisible taking into account their nature and characteristics the travel providers as well as travel intermediaries are looking for partners in highly competitive tourism market. Under such a delicate cooperative relationship, the travel intermediaries and as well as service providers (hotels, tour operators, airline companies) must understand key role and market postion within industrial network guaranteed by business purpose, by standardized services with no variation of qualities offered, addied values seen as advantages in time saved when inform about packages, destinations and specialized activities targeted to market niches. Specialization of product programs of package tours should be based upon on the diversification and an innovative way of placements of products and services aimed at the target market segments. The role of a tourist intermediary is realized through communication with consumers, sales and booking. Under market changes, changable preferences of consumers, travel agencies need to transform their activities [13]. Travel agencies trying to maintain their competitive advantages and survive the fierce competition, must have their own unique, inimitable and valuable resources. In parallel, competitors share the market with each other and pool the clients to organize a tour for groups. In this way, travel agencies form a special cooperative and competitive relationship between each other. In response to their interdependency on resources among industry players, travel agencies jointly promote the package tour. The relationship between enterprises is cooperating and competing to obtain resources and determine what resources should be acquired [14]. As complementary resources refer to the resources provided by a partner and considered unique by other partners, the competitive advantage of companies derive from sharing them , combining their advantages to achieve business goals [15] common goals. The competitive advantage must be put on mutually complementary resources that partners have, co-creating of more new energies [16].

At the same time the exchange of complementary resources can spread risks, increase market influence, remove barriers to entry and increase economic sizes, R \& D activities,and production activities [17].Considering the resource dependence, complementary resources are the ones needed for survival and reduce environmental uncertainties .Travel agents should seriously consider conducting strategic alliances to ensure the availability of resources and to evaluate the needed complementary resources, capabilities for increased "premium speed" in business in dynamic market conditions during crises. Only in this way can they synergize and have a lasting competitive advantages. Specialisation refers to smart or specialised diversification around identified related activities/themes that are often defined as priority areas of regional specialisation that is not only the most dominant regionally embedded, but also likely to stimulate high growth and further relatedness between sectors leading to further diversification aiming to identify new opportunities [18] It is resulting by creativity.

The motivation and the decisions of tourists are defined by specific interests that are focused on the specific activity or multiple activities.As a key driver of tourism development specialization in tourism is motivated by the need for including tourists in new experiences or to develop new activities in the destination.. The offer of "special interests" can be found on the most websites of intermediaries and specialized for particular types of tourism in order to satisfy the specific group of tourists. This contribute to definition of specialization of products (packages) and services of travel intermediaries that are found on a way of their evolution. Regardless of the number of service providers who are actively participating in the creation of the sense - "experiences and amenities" - travel packages as a consequence of the process of transformation of needs and possibilities has not completed its evolutionary process. A part of responsibility for adaptation of the tourist product, intermediaries receive the treatment in:

a) the assumption of specialization that should give answers to the questions in relation to the requirements and interests of both poles of the tourism market ,

b) the assumption of technological efficiency in terms of the acceptability of tourist products 
wherein an emphasize is on meeting satisfaction of tourists -providing information, an efficient communication process up to the ways of travel organization .

\section{Data and methodology of research}

In order to test the significance of the hypothesis $\mathrm{H})$, according to Structural changes in the tourism market influence the specialization of business of travel intermediaries; a survey on attitudes of tourists highlighted findings of level of product specialization of travel intermediaries in Dubrovnik A suitable sample was chosen as the sampling method The hypothesis was tested with the empirical method of interviewing the tourists in Dubrovnik. The target population for the given research was a set of tourists who visited Dubrovnik Elementary unit of the survey to be selected in the sample is defined as the respondent - tourist who stayed for a shorter or longer period. Before participating in the survey, respondents had been asked whether they had been spent one overnight or more in Dubrovnik, or elsewhere. Tourists who had not been spent at least one overnight in Dubrovnik were not been included in the survey. Pilot testing of the questionnaire was conducted. The optimal number of questions was determined with the aim of reaching the highest possible concentration of respondents while collecting the appropriate data number in the shortest possible time. The questions were simplified to make the survey clearer to the respondents, but with the necessary level of complexity that allows an unambiguous understanding of the question.

For that purpose, the questionnaire was designed from 5 groups of questions: a) Basic information about respondents; b) Determinants of travel decisions (2 questions); c) Questions concerning tourist behavior in Dubrovnik (4 questions);

Questions concerning the reasons for coming to Dubrovnik and the sources of information used (2 questions); Questions about the organization of the stay in Dubrovnik (12 questions).The questions were raised in three possible ways:

a) open-type of questions ;

b) closed-type of questions, with an option of choice of one or more predefined categorical statement or the same type of questions where participants had to agree or disagree with predefined assertions Likert scale;

c) closed-type of questions in accordance with predefined statement.

Descriptive and inferential statistical methods were used for data analysis. The survey was completed using the statistical package SPSS ver. 18 , using descriptive and inferential statistics methods. Based on the data collected through the survey, the hypothesis of this paper was tested, using multiple logistic regressions. The method was chosen following the nature of the dependent variable, which is a binary-type sequence and nature of the independent variables, which are numerical type. Multiple logistic regression as a statistical method is suited and usually used for testing hypothesis about relationships between 1) a categorical dependent variable ${ }^{1} \mathrm{Y}$ or an outcome variable and 2) more categorical or continuous predictor or $\mathrm{k}$ independent variables ${ }^{2} \mathrm{X}_{1}, \mathrm{X} 2, \mathrm{Xk}$, za $k \geq 2$ that can be quantitative (with fewer or more values), or qualitative (with two or more categories). The dependent variable $\mathrm{Y}$ in logistic regression is binary or dichotomous.. The maximum likelihood method, which yields values for the unknown parameters, is used for estimating the least squares function. Logistic regression solves such problems applying the logit transformation. Logistic regression predicts the logit of $\mathrm{Y}$ to $\mathrm{X}$. The relationship between the dependent and independent variables is not of a linear type. In regression type models, the probability of achieving one of the possible outcomes of a binomial dependent variable is estimated, provided that the independent variables have certain values:.

$$
\mathrm{P}(\mathrm{Y}=1 \mid \mathrm{X})=?, \mathrm{X}=\left[1, \mathrm{X}_{1}, \mathrm{X}_{2}, \ldots, \mathrm{X}_{\mathrm{n}}\right]
$$

In accordance $\mathrm{P}(\mathrm{Y}=1 \mid \mathrm{X})$ number with values from interval $[0,1]$, and it is is valid

$$
P(Y=1 \mid X)=f\left(a_{0}+a_{1} \times X 1+a_{2} \times X 2+\ldots+a_{n} \times X_{n}\right)
$$

Where a0, a1,.., an, represent the estimated parameters with independent variables. To ensure the required interval as a set of values, the function $\mathrm{f}$ of the above expression must be: f: $\mathrm{R} \#[0,1]$

Figure 1 Logistic connection function as function of a common S-shaped curve

\footnotetext{
${ }^{1}$ The dependent variable is also related to the regresand or endogenous variable 2 . Independent variables are also called regressor variables or predictor variables.
} 


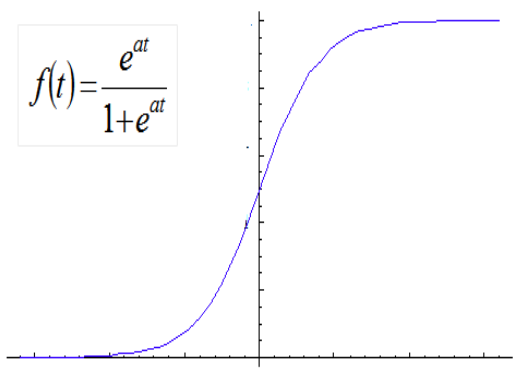

If the dependent variable $\mathrm{Y}$ is qualitative in the logistic regression model, it can take only two categories, i.e., binary values, (for example: Someone "has" $=1$ or "none" $=0$, "uses" $=1$, or "does not use" $=0$, someone "belongs" to something $=1$ or "does not belong" $=0$, etc). The relationship between the binary dependent and the independent variable is not of a linear type but it is described by an "S" curve; where the $\mathrm{S}$ curves shown have asymptotes 0 and 1 . In this case, the conditional probability of the outcome "Y = 1" given the value of the independent variable is the number from the interval [0.1].

As Šošić pointed[19]:

$$
\begin{gathered}
E[Y \mid X]=\frac{1}{1+\exp (\alpha+\beta X)^{-1}}, \\
\text { Respecting: } \\
E[Y \mid X]=\frac{\exp (\alpha+\beta X)}{1+\exp (\alpha+\beta X)},
\end{gathered}
$$

Where $\alpha$ and $\beta$ are parameters and exp is the base of the natural logarithm. Here $\alpha$ is a constant and $\beta$ is a parameter with an independent variable. For $\mathrm{k}$ independent variables, the parameters with individual independent variables are denoted as: $\beta 1, \ldots, \beta \mathrm{k}$, respectively: $\beta \mathrm{j}$, for $\mathrm{j}=1,2, \ldots, \mathrm{k}$.

Most often, unknown parameters from the logistic regression model are assessed by Maximum likelihood (ML) method of estimation. The regression equation for the $\mathrm{S}$ probability outcome curve " 1 " with one independent variable $(\mathrm{k}=1)$ is as follows

$$
p=\frac{e^{(\alpha+\beta x)}}{1+e^{(\alpha+\beta x)}},
$$

while for $\mathrm{k} \geq 2$, the following applies:

$$
p=\frac{e^{\alpha+\beta_{1} x_{1}+\ldots+\beta_{k} x_{k}}}{1+e^{\alpha+\beta_{1} x_{1}+\ldots+\beta_{k} x_{k}}} \cdot
$$

For the purposes of this paper, the selected multiple logistic regression method was derived from the nature of the binary-type dependent variables and the nature of the numericalindependent variables $(k>2)$.Different values of the dependent variable are not estimated, as in the usual multiple linear regression, but rather the probability ( $p$ ) is estimated that the dependent variable will receive a value of 1 rather than 0 (ie it will fall into one category instead of the other).The multiple logistic regression model with estimated parameters for $\mathrm{k} \geq 2$ independent variables is:

$$
\hat{p}=\frac{e^{\hat{\alpha}+\hat{\beta}_{1} x_{1}+\ldots+\hat{\beta}_{k} x_{k}}}{1+e^{\hat{\alpha}+\hat{\beta}_{1} x_{1}+\ldots+\hat{\beta}_{k} x_{k}}},
$$

wherein the parameter estimation - obtained by the maximum likelihood method. Logistic regression involves adjusting the equation:

$$
\log i t(p)=\hat{\alpha}+\hat{\beta}_{1} X_{1}+\ldots+\hat{\beta}_{k} X_{k} .
$$

The quality of the estimated model is most often estimated using the Nagelkerke R Square indicator which gives an indication of the proportion of variation of the dependent variable explained by the multiple logistic regression models. This indicator takes values from minimum - 0 to maximum - 1. As such, it resembles the coefficient of determination of R2 from the commonly used multiple regression model. This indicator is preferably being as higher, i.e. the closer to 1 that state- better Logistic regression models. The influence of individual independent variables on the binary dependent variable $\mathrm{Y}(\mathrm{Y}=1 ; \mathrm{Y}=0)$ is tested by a Wald test, based on test size of the following form: Wald test size $=$ (parameter estimation / standard error of parameter estimation $)^{2}$.

This is based on the following hypothesis:

HO: independent variable $X j$ is not statistically significant for explaining variations of the dependent variable, ie it does not affect the dependent variable

H1: independent variable $X j$ is statistically significant for explaining variations of the dependent variable, i.e. it affects the dependent variable

\subsection{Data on a sample of survey}

For testing the hypothesis according to which $(\mathrm{H})$ : Structural changes on the tourism market impact on the specialization of business of travel intermediaries; an appropriate sample was chosen as a sampling method. Reporting units in this research are represented by respondents i.e. tourists who were interviewed during their stay in the tourist destination of Dubrovnik. A suitable sample was chosen as the sampling method. The pattern sought to include tourists staying shorter or longer period. Before participating in the survey respondents were asked if they would spend one overnight or more, in Dubrovnik, or elsewhere. 
Tourists who had not been spent at least one overnight in Dubrovnik, they were not included in the survey. Since the sample comprised 400 respondents, a survey involved tourists who were sightseeing in Dubrovnik, and who were asked prior to the survey if they were staying in Dubrovnik or elsewhere. In doing so the hypothesis was tested with the originally empirical method of interviewing the tourists in Dubrovnik.

A survey method was used to collect data in the research. Research goals determines the selection of the sample and tourists as elementary unit of statistical reserach, that indicates the validity of the survey sample and number of respondents that suport the representativeness of the same. The share of $(76 \%)$ belongs to those who used travel intermediaries as the organizers of their travel, pointing out the full service usage of travel packages or partially organized products with higher posibillities of personalization and specialization. The subject-matter was designed to contain: a) the basic information about respondents, b) reasons that impact on choosing Dubrovnik as tourist destination, way of travel booking and organization; key sources of information that influenced on travel decision making process, activities within packages that were used as modalities of structural changes in preferences of tourists that could influence the level of business specialization of travel intermediaries The elementary unit selected into the survey sample is defined as a tourist who visited Dubrovnik, tourists who were sightseeing Dubrovnik, and who were asked prior to survey if they were staying in Dubrovnik.

Tourists who did not stay overnight were not included in survey. The survey covers tourists who represent different demographic features) country of origin ); gender (male, female); qualifications (secondary education,university degree, other, no answer); and characteristics related to the stay in the destination: travel organization (travel agency, individually); means of transportation (car, bus, plane ), stay in Dubrovnik (the first time, several times); travelling in the company (alone, with friends or partners, with family); overnights in Dubrovnik (less than 4, 4-7, more than. It was conducted a pilot test of the questionnaire, which determined the optimum number of issues. The aim was the achieving of greater concentration of respondents to the collection of an appropriate number of data in the shortest possible time. Formulation issues enabled the clarity of the survey respondents, whereby certainly provided unambiguous understanding of the issues. Data entry and processing of the survey was conducted using the statistical package SPSS ver. 18th, applying the methods of descriptive and inferential statistics. Based on data collected through the survey research, the hypothesis of this study was tested. In doing so, it was developed a model of multiple logistic regression. The method was chosen following the nature of the dependent variable, which is a binary-type sequence and nature of the independent variables, which are numerical type.

The demographic profile of the respondents speaks in favour of the characteristics of tourists related to emitive tourist markets, given their proportion in the overall structure of tourists from the sample who stayed in the destination, gender (male, female); education and professional qualification of tourists - qualifications (secondary education, university degree, other, no answer). In accordance with Eurobarometer [20] new travel markets have exceptional potential of growth. Considering the gender the share of $(56 \%)$ of respondents in the sample belongs to the female, and $(44 \%)$ to the male.

The results of the analysis of the structure of respondents by country of origin speak in favour of $(27 \%)$ of respondents from the UK who has high position, following by Germany (6\%), France $(7 \%)$ and the US (8\%). It is interesting to observe the share of Scandinavian tourists (Finland $8 \%$, Norway 3\% Denmark 3\%, Sweden 2\%) and a slightly lower structure from traditional Italian markets $(3 \%)$ in the overall structure of respondents. There is a trend of increasing popularity of Croatia in interesting markets as Japanese 5\%, Korea\% 7\%, Australia 6\% but also the expansive growth of tourists from the BRIC market 13\% (Brazil 3\%, Russia $4 \%$, India 3\% China 3\%). Results supported by secondary research speak in favour of visible changes in shares from individual markets in the overall structure of respondents, that contributed by the expansive growth of tourists from distant markets and newer markets such as Japan, Korea, BRIC markets and Australia. Since the identity in Dubrovnik has been defining on specific cultural assumptions, it is expected that tourists who have university degree (44\%), the respondents who have a high school education (17\%), visit Dubrovnik.

Given the characteristics of the stay, the analyzed sample speaks in favour of the characteristics of tourists related to the predominant organization of travel (travel agency, independent), used means of transport (car, bus, 
plane), stay in Dubrovnik (first time, several times), arrival (alone, with friends or partners, with family), number of overnight stays (less than 4, from 4 to 7 days, more than 7 days). Table 1 shows the structure of respondents considering the characteristics of their stay in Dubrovnik.

Table 1. Structure of respondents considering the characteristics of stay in Dubrovnik

\begin{tabular}{|c|c|c|c|}
\hline & & $\mathrm{N}$ & $\%$ \\
\hline \multicolumn{2}{|l|}{ TOTAL } & 327 & $100 \%$ \\
\hline \multirow{2}{*}{$\begin{array}{l}\text { ORGANIZATION OF } \\
\text { TRAVEL }\end{array}$} & Travel Agency & 248 & $76 \%$ \\
\hline & Independent & 79 & $24 \%$ \\
\hline \multirow{3}{*}{$\begin{array}{l}\text { MEANS } \\
\text { TRANSPORT }\end{array}$} & Car & 45 & $14 \%$ \\
\hline & Bus & 13 & $4 \%$ \\
\hline & Plane & 269 & $82 \%$ \\
\hline \multirow{2}{*}{$\begin{array}{ll}\text { STAY } & \text { IN } \\
\text { DUBROVNIK } & \end{array}$} & First time & 260 & $80 \%$ \\
\hline & Several times & 67 & $20 \%$ \\
\hline \multirow{3}{*}{ ARRIVAL } & Alone & 25 & $8 \%$ \\
\hline & $\begin{array}{l}\text { With friends } \\
\text { or partners }\end{array}$ & 201 & $61 \%$ \\
\hline & With family & 102 & $31 \%$ \\
\hline \multirow{3}{*}{$\begin{array}{lr}\text { NUMBER } & \text { OF } \\
\text { OVERNIGHT STAYS }\end{array}$} & Less than 4 & 65 & $20 \%$ \\
\hline & $4-7$ & 173 & $53 \%$ \\
\hline & More than 7 & 89 & $27 \%$ \\
\hline
\end{tabular}

Source: Author's analysis of survey

The most common means of transportation by which the respondents travelled is a plane, $(82 \%)$, followed by car (14\%) and even to a lesser extent the by bus (4\%). Referring on data according to which the plane used the $(82 \%)$ of respondents, Dubrovnik will continue to evolve as an airline destination. Because of its distance from the emitive tourist markets, travel costs could play an important role as an argument for choosing destination considering the distance. In accordance with, it is important that own specific identity based on spatial feature of "continuing attractiveness" and elements that contribute to the ambient experience, should intertwine in destination product. That builds loyalty of tourists with the destination - with the specific image. Most of tourists are for the first time in Dubrovnik $(80 \%)$, while the $1 / 5$ of respondents already stayed in this destination (20\%). The respondents most often come with their friends and partners $(61 \%)$, and less with their family (31\%). Less than $\square$ of the cases, come by themselves (8\%). Tourists who were surveyed in more than a half of respondents spent in Dubrovnik between 4 and 7 nights (53\%) and it is an equal number of those who stayed longer or shorter (less than 4 or more than 7 days). The results of the research are in correlation with world travel trends. Tourists in Dubrovnik make several shorter trips a year instead of one longer one. Even $(77 \%)$ of respondents choose two or more trips per year, while only $(23 \%)$ of respondents opting for a trip. The distance is also criteria when choosing means of transport. The share of tourists that stay in Dubrovnik under organization of travel agencies (75\%) indicates that the destination of Dubrovnik is too far from emitive tourist countries (from which tourists arrive)

\subsection{Results}

\subsubsection{Attitudes of tourists about the reasons of coming to Dubrovnik}

Considering the demographic characteristics of the respondents, the main reason for coming to Dubrovnik is leisure, stated by the largest share of respondents $(63 \%)$, followed by new experiences (32\%) and culture (27\%) follow. Other reasons were given in less than one tenth of the respondents. Gathering experiences and motivated by specific values that shape and create an authentic product in the destination, tourists are searching for the excellence in the destination that is mostly found in time benefits, products that are in compromise with spent financial funds. Financial moment as an important critical factor is described by the expected sum of money planned to be spent buying specific tourist products in the destination, constructing the destination consumption. Figure 2 shows the structure of respondents considering the reasons of coming to Dubrovnik.

Figure 2 Structure of respondents considering the reasons of coming to Dubrovnik

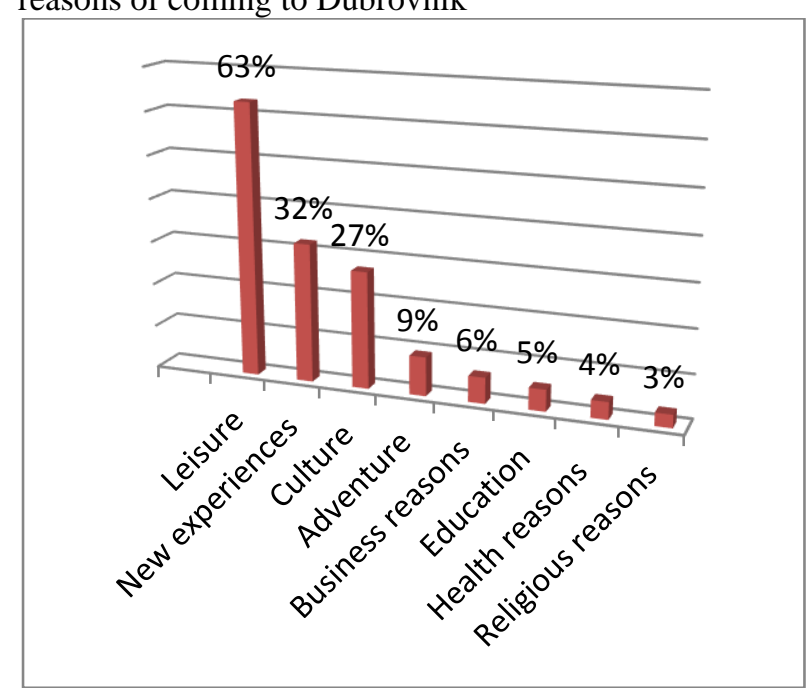

Source: Author's analysis of survey

Women share attitudes in (74\%) that the most important reason for coming to Dubrovnik is free 
time compared to men (55\%). They show an increased interest in active forms of products diverse from standardized tourism products, whether the specialization of activities of providers related on specific types of arrangements with "represented specific travel themes" such as affinity or hobby arrangements. Such assumptions are an incentive to create quality products and to continuing process of diversification. As pointed out, the reasons that encourage tourists from Scandinavia to come to Dubrovnik refer to desire to gain new knowledge and experiences (47\%), curiosity and willingness to explore new areas other than their home countries. Furthermore, cultural factors in Dubrovnik support the cultural and originally traditionalist motives (47\%) of this marketing segment. Destination Dubrovnik abounds in specific resources that offer historical legends as immaterial heritage and facilities in accordance with the expectations of the above segments of tourists.

Considering the characteristics of the stay and organization of travel, tourists who came by travel agency $(63 \%)$, state the use of free time as the most important reason for coming to the destination. On that basis, the offer of (integrated) tourist products of travel intermediaries with such specific activities should be represented, which will professionally unite all the required services and include the specifics of the destination features in the activities of their own products. Trust and the guarantee of quality of services assure loyalty. They are the main trump cards on which the travel agency builds its business. The largest number of tourists, who argued a free time as the main reason for coming to Dubrovnik, use the plane as a means of transport $(68 \%)$. None of the tourists use the bus if the reasons for arrival and travel are related to the adventure or the work. The share of respondents who visited Dubrovnik for the first time is higher than those who have already been, regardless of whether the reason for coming is free time, work, culture, new experiences, adventure, education, health or religious reasons. Approximately, it is the same share of tourists (66\%) who stay in Dubrovnik for less than 4 or more than 4 nights, and who cited free time as the reason for coming to Dubrovnik. The share of (37\%) of tourists who stay more than 7 nights pointed out cultural reasons as the reason for coming to Dubrovnik.

\subsubsection{Sources of information about travel and destination of Dubrovnik used by tourists}

As a source of information about Dubrovnik and travel to Dubrovnik, respondents mostly (53\%) used information and advice from travel agencies. This speaks in favour of the dominance of intermediaries as a traditional distribution channel that uses in a complementary way the advantages of the Internet in communication and information with end consumers. This research finding confirms that tourists use traditional information channels for those destinations that ultimately decide to visit. Tourist fairs, brochures, advertisements and posters were used as a source of information by one tenth of the respondents, and the previous visit was stated by $5 \%$ of the respondents.

Figure 3 The share of respondents considering the most important source of information used before travel in Dubrovnik

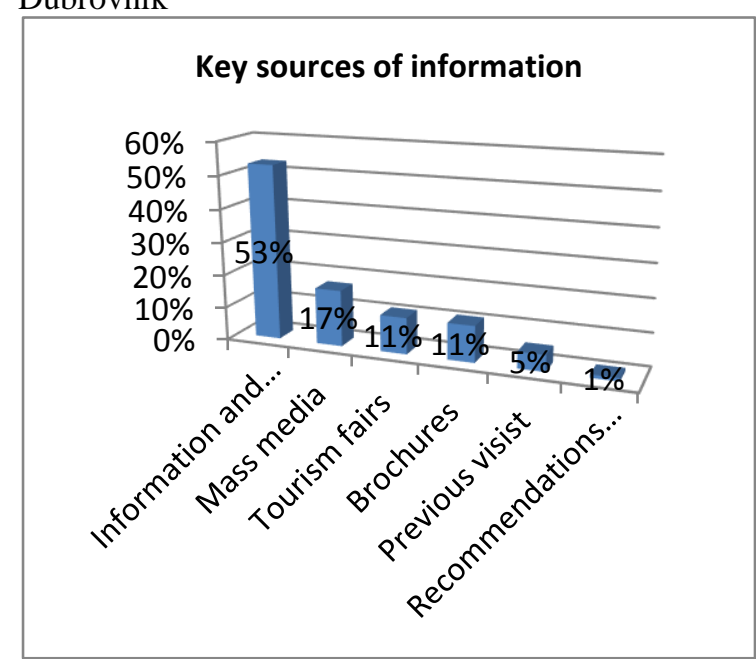

Source: Author's analysis of survey

There is quite a big difference in the choice of sources of information according to the country of the arrival of tourists argued by demographic characteristics. Considering the previous attitude, tourists from the United Kingdom (61\%), Scandinavians $(56 \%)$, tourists from Germany (54\%), and (79\%) tourists from America, use travel agencies as the key source of information when decide about destination when planning trips.. Communication with professional employees and useful advices influence on the trust, building loyalty through the assistance. There is no doubts that this strengthens the sense of security in the reliability of the quality of services and creates loyalty in the expectance of values of products. The information-advisory function of a travel agency is based on 
fundamental role of intermediaries that are evolving towards the service quality. The distance of emitive from receptive tourist markets represents the time and space gap that the travel agencies (by permeating its functions, intensifying the area of work) successfully manage, making at the same time information more accessible, faster and of better quality. With regard to education, (64\%) of tourists are with the university degree and who are informed using travel agencies when choosing this destination. The choice is influenced by the distance of the emitive markets, but also by an assumption that their overall tour or partly, will be organized by same the travel agency. Given the characteristics of the stay, information and advices of travel agencies as an important source of information was used even by $(73 \%)$ of those who visited this destination in an individual way of organizing travel. In this way, they reduced the level of uncertainties regarding the receipt of the service, expectations related to the standardized service quality. This creates the possibility of using some services and partial products of intermediaries who use modern tools in the placement of partial products and services. A travel agency (59\%) mostly informed tourists who used car as the means of transport, while an equal share of tourists who came by car were informed through brochures or based on previous visits (13\%). The largest share of tourists coming to the destination for the first time is informed using travel agencies (55\%). Information through brochures and posters is mostly used (47\%) by tourists who have already been to Dubrovnik

\subsubsection{Basic activities of package tours used by respondents in Dubrovnik}

Respondents were asked to indicate which basic activities have been included in their package tours Figure 4 . The largest number of respondents pointed out a trip (31\%) near Dubrovnik, culture (23\%), and only a small share of respondents stated sports activities (6\%), and sightseeing (3\%). Considering the demographic characteristics of the respondents, the main activity included in the package tours are cultural events mostly mentioned by tourists with a university degree $(30 \%)$. On that basis should be considered future majority of activities. There is an equal share of persons of both gender for whom the activities of package tours related to sports $(6 \%)$ and sightseeing (3\%) are important. Below figure 4 shows the share of respondents with regard to the basic activities of package tours in Dubrovnik
Figure 4 The share of respondents with regard to the basic activities of package tours in Dubrovnik

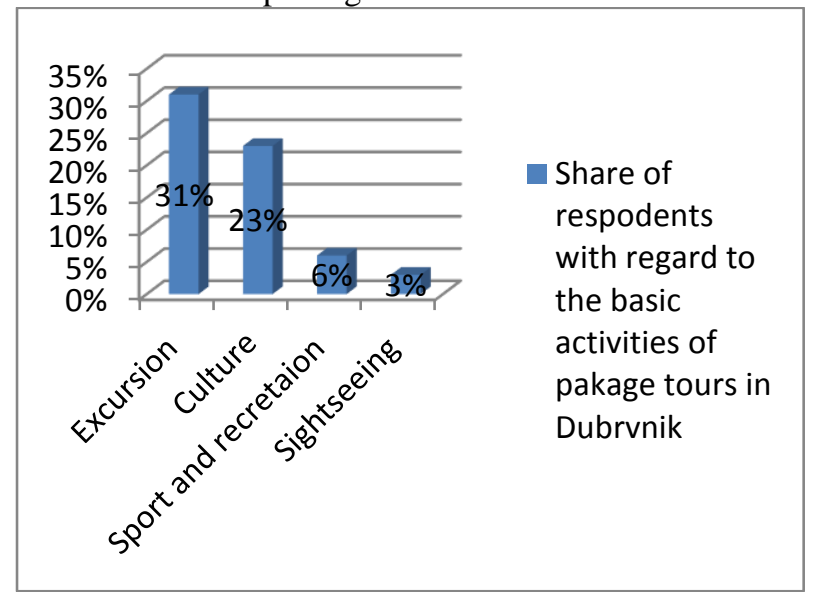

Source: Author's analysis of survey

Given the criteria of characteristics of stay in Dubrovnik, when choosing an excursion as a basic activity embodied in package tours, the largest share of tourists belongs to those that arrive by plane $(32 \%)$. Tourists, whose packages are dominated by excursion activities (33\%) and cultural events (27\%), are those that are for a first time in Dubrovnik. Most often, participating with (39\%) - tourists who stay in Dubrovnik from four to seven days undertake an excursion as a basic activity of the package. There is a very small share of tourists who consider sightseeing as a basic activity within a tourist arrangement $(5 \%$.) These data support "excursions" as an activity - content that dominates in most responses, which is a logical consequence of the assumptions created in a natural environment, diverse spatial possibilities in close localities with possibilities of substitution but that provide a characteristic atmosphere of indigenous space. The significance of cultural events within the package tours and the higher efforts in engagement of organization of activities are stated. It would stimulate and encourage participants with differ interest of tourists, opening capabilities for valorisation of the unique indigenous tourist products. Gathering experiences, motivated by events and experiences, tourists through participation in the activities of the package arrangement actively participate in creating an authentic product in tourism. The diversity of market niches, different preferences and interests, are an additional challenge for:

a) Space, to develop the offer of special experiences, 
b) Stakeholders who are given the opportunity to offer special products and to coordinate and integrate their interests for the benefit of the public good and the sustainable development of the destination's products,

c) Those travel agencies that seek excellence in the field of production and sales of the original specialized tailor made product - the package tour.

\subsubsection{Other facilities used by tourists during their stay in Dubrovnik}

Other contents mentioned by the respondents and used in Dubrovnik refer to: excursions (42\%), shopping (37\%), cultural and entertainment contents (33\%), and sports and recreation (17\%). A small proportion of respondents $(1 \%)$ reported sailing and rent-a-car. In doing so, it would be especially important to encourage the production of original indigenous products from the area of Dubrovnik. Considering demographic characteristics and the share of respondents that stated specific additional activities used when staying in Dubrovnik, it is approximately equal share of tourists $(62 \%)$ from the Scandinavian countries and UK (61\%) who prefer the use of excursions as additional facilities in the destination. The largest share of tourists $(61 \%)$ from the United Kingdom cited shopping as an important component of travel.

Tourists with a university degree prefer shopping (45\%), culture and entertainment (42\%), while tourists with a university degree give emphasis to the additional facilities in the destination with excursions.

Given the characteristics of the stay and the share of respondents who listed certain additional facilities they used during their stay in Dubrovnik, the share of tourists who use an aircraft as a means of transport is $(41 \%)$ much higher when the additional content of their stay is shopping. Approximately the same share of tourists (32\%) comes for the first time or it has already been in Dubrovnik, and prefers the stay included cultural events.

\subsubsection{The structure of the way of booking of travel accommodation in Dubrovnik}

Respondents were asked to indicate how they booked accommodation in Dubrovnik, and it was shown that under half of the cases, respondents booked accommodation through the travel agency (46\%) and through a tour operator (24\%). A smaller number of respondents made an independent booking via Internet (24\%) and by direct inquiry (6\%). Considering the demographic characteristics of the respondents and the way of booking accommodation in Dubrovnik, tourists from Russia in share of $(75 \%)$ use the services of the travel agency. Considering the gender, in approximately equal shares, tourists book accommodation through the travel agency (44\%), while $(26 \%)$ of tourists book it through the tour operator (24\%), via Internet and (6\%) through the direct request.

Considering the characteristics of the stay, travel agencies have dominant role in organization of travel and stay in the destination of Dubrovnik, using some services, partial packages (some services of travel intermediaries) or full package tours. The largest share of tourists $(63 \%)$ who booked accommodation through the travel agency comes to Dubrovnik with their family. The way of booking accommodation through travel intermediaries (TO \& TA) is the choice of (31\%) of tourists that travel with friends or partners. The largest share of $(59 \%)$ of tourists who undertakes an independent travel, also use Internet booking and booking. If respondents booked service through the travel agency, they rated an extremely important element of innovation and transparency that helps them being informed on their partial products through intermediaries, which confirms the importance of using of modern technology in modern business. The possibility of personalization of excursion using additional contents will complete the overall experience realized through online booking and quality of information. This further emphasizes the importance of specialization and adaptation of travel agencies to modern trends in the tourism market. Respondents still use the oldest advisory function of travel agencies, but not through traditional sources of information such as brochures, but through innovative modalities using ICT $(48.9 \%)$. In order to research the suitability of travel agents to the preferences of respondents with regard to personalizing their travel and the use of additional services such as excursions, museum visits and other services as part of their package, the results speak in favour of personalizing their travel. Products that use new technologies offer innovative modalities of purchasing of partial products with agrees of $(61 \%)$ of respondents. (76\%) of respondents were satisfied or very satisfied with the level of specialization of their excursion.

In the share of the certain partial product of travel agency that are crucial for choosing a travel agent, traditional services of accommodation and 
transport dominate each with $95.6 \%$ and $97 \%$, while $48.9 \%$ of tourists use the advisory services of travel agency. Every with every fifth answer is based on intermediation in online selling for additional content that most often concerns special content in the destination and diversification of the offer in the destination.

\subsubsection{Attitudes of tourists considering the level of specialization business of travel intermediaries}

In order to examine The impact of structural changes in the tourism market on the specialization of the business of travel intermediaries in the tourist destination, the following aspects have been analyzed::

[1] Travel agency program specialization,

[2] Significance of selected contents related to the stay in the destination

[3] Recommendations of tourists for improving the quality of the package tours in Dubrovnik.

Attitudes of tourists about the level of specialization of the program of travel agencies

Respondents were asked to assess the extent to which travel agencies have specialized their programs (Figure 5). It was shown that one third of agencies (32\%) have a partially specialized program, two fifths of agencies have a program according to respondents' wishes and expectations (44\%), while only one quarter of respondents do not have a specialized program $(24 \%)$.

Figure 5 The share of respondents with regard to the specialization of the program of travel agencies

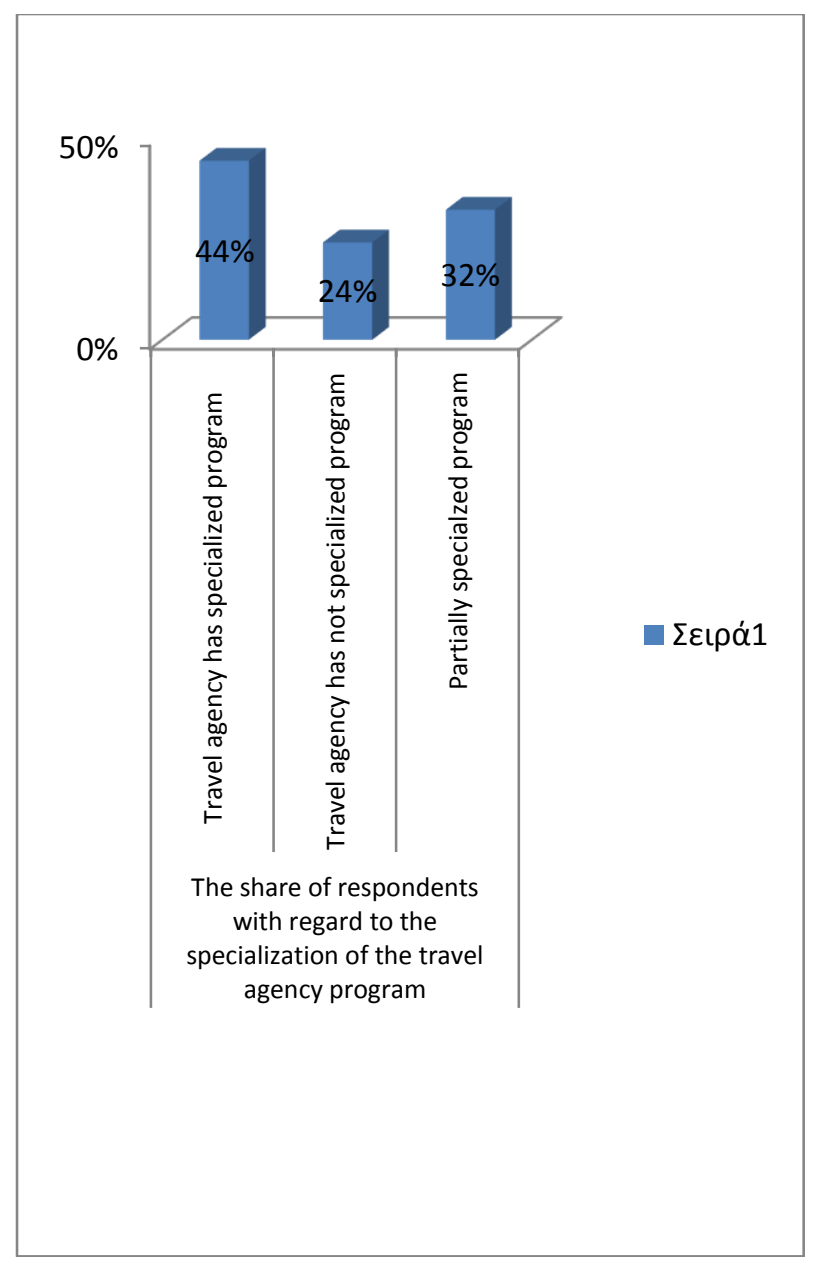

Source: Author's analysis of survey

Approximately, there is the same share of tourists $(45 \%)$ travelled by plane and by car (43\%) and who state that travel agencies have a program according to their wishes (Table 2) Tourists who have been visiting Dubrovnik more than once, given their experience, in a larger share $(61 \%)$ point out that travel agencies have a program tailored to their preferences. Demographic characteristics of the respondents with regard to the specialization of the program of travel agencies, speak in favour of the share of $(33 \%)$ of tourists from the United Kingdom, (44\%) from Germany, and (76\%) from Russia who stated that the travel agency had a specialized program.. There is a higher share of women (29\%) compared to men (19\%) who have the opinion that a travel agency does not have a personalized and specialized program. The largest share of tourists with a university degree (48\%) has stated that travel agencies offer programs tailored to their needs and desires.

Table 2 Specialization of programs of travel agencies characteristics of stay 


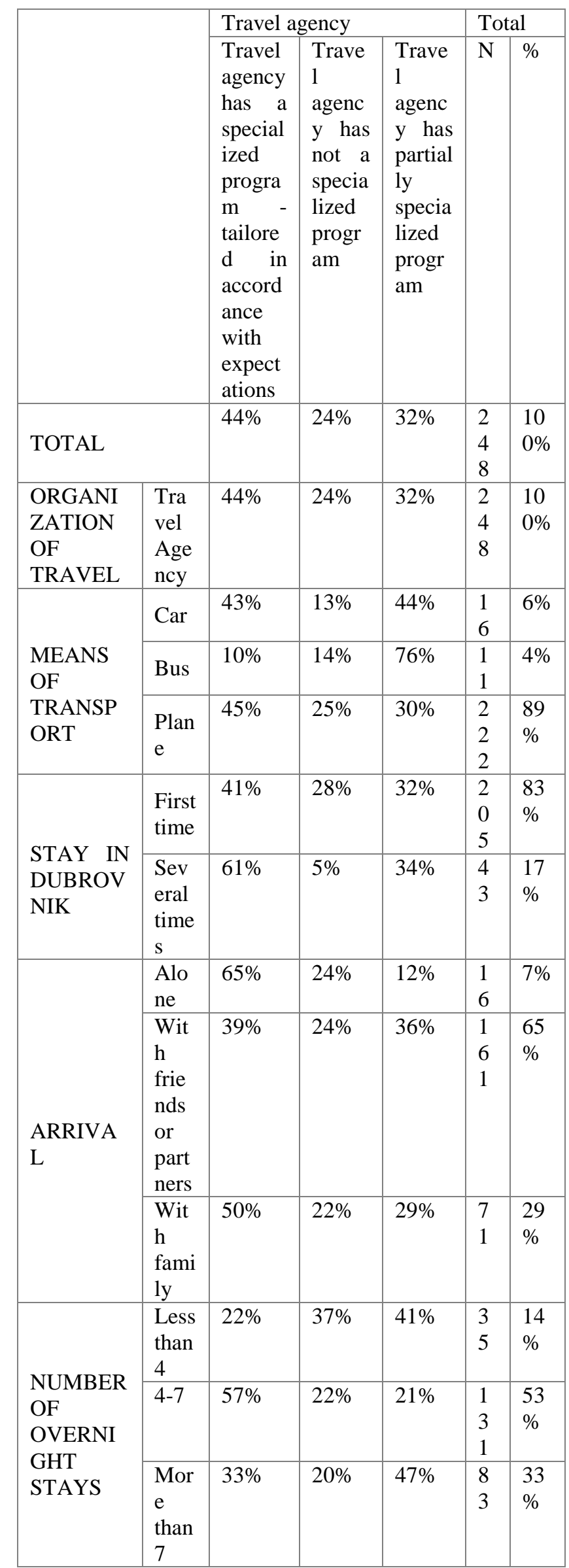

Source: Author's analysis of survey
Respondents were asked to rate the importance (for their stay) of certain activities organized by travel agencies in Dubrovnik including (health and recreation program, sailing, adventure sports, rafting and the importance of participating in concerts and festivals). The highest average ranking was achieved for concerts and festivals (2.91), followed by the health and recreation program (2.68). A slightly lower rank was achieved for adventure sports and rafting (2.23), and for sailing (1.91).Table 3 shows the ranking of activities according to the degree of their importance, supported by attitudes of respondents with regard to the significance of selected contents during their stay in Dubrovnik 
Table 3. Ranking of activities according to the degree of importance (respondents arrived through the travel agency) - average rank of importance (1-most important, 4-least important) - characteristics of the stay

\begin{tabular}{|c|c|c|c|c|c|}
\hline & & $\begin{array}{l}\text { Health } \\
\text { and } \\
\text { recreat } \\
\text { ional } \\
\text { progra } \\
\text { m }\end{array}$ & $\begin{array}{l}\text { Sail } \\
\text { ing }\end{array}$ & $\begin{array}{l}\text { Adve } \\
\text { nture } \\
\text { sports } \\
\text { Raftin } \\
\mathrm{g}\end{array}$ & $\begin{array}{l}\text { The } \\
\text { importa } \\
\text { nce of } \\
\text { particip } \\
\text { ation in } \\
\text { the } \\
\text { concert } \\
\mathrm{s} \text { and } \\
\text { festival } \\
\mathrm{s}\end{array}$ \\
\hline TOTAL & & 2,68 & 1,91 & 2,23 & 2,91 \\
\hline $\begin{array}{l}\text { ORGANIZ } \\
\text { ATION OF } \\
\text { TRAVEL }\end{array}$ & $\begin{array}{l}\text { Trav } \\
\text { el } \\
\text { agen } \\
\text { cy }\end{array}$ & 2,68 & 1,91 & 2,23 & 2,91 \\
\hline \multirow[t]{3}{*}{$\begin{array}{l}\text { MEANS } \\
\text { OF } \\
\text { TRANSPO } \\
\text { RT }\end{array}$} & Car & 3,67 & 3,12 & 2,50 & 2,80 \\
\hline & Bus & 2,62 & 3,00 & 2,00 & 2,50 \\
\hline & $\begin{array}{l}\text { Plan } \\
\text { e }\end{array}$ & 2,64 & 1,83 & 2,22 & 2,92 \\
\hline \multirow{2}{*}{$\begin{array}{l}\text { STAY IN } \\
\text { DUBROV } \\
\text { NIK }\end{array}$} & $\begin{array}{l}\text { First } \\
\text { time }\end{array}$ & 2,73 & 1,78 & 2,27 & 2,86 \\
\hline & $\begin{array}{l}\text { Seve } \\
\text { ral } \\
\text { time } \\
\mathrm{s}\end{array}$ & 2,41 & 2,55 & 2,03 & 3,16 \\
\hline \multirow[t]{3}{*}{ ARRIVAL } & $\begin{array}{l}\text { Alo } \\
\text { ne }\end{array}$ & 1,99 & 1,64 & 2,76 & 3,18 \\
\hline & $\begin{array}{l}\text { Wit } \\
\mathrm{h} \\
\text { frien } \\
\mathrm{ds} \\
\text { or } \\
\text { part } \\
\text { ners }\end{array}$ & 2,73 & 1,86 & 2,03 & 2,82 \\
\hline & $\begin{array}{l}\text { Wit } \\
\text { h } \\
\text { fami } \\
\text { ly }\end{array}$ & 2,76 & 2,07 & 2,42 & 3,00 \\
\hline \multirow{3}{*}{$\begin{array}{l}\text { NUMBER } \\
\text { OF } \\
\text { OVERNIG } \\
\text { HT } \\
\text { STAYS }\end{array}$} & $\begin{array}{l}\text { Less } \\
\text { than } \\
4\end{array}$ & 1,58 & 2,32 & 2,68 & 2,57 \\
\hline & $4-7$ & 2,71 & 1,81 & 2,35 & 3,08 \\
\hline & $\begin{array}{l}\text { Mor } \\
\text { e } \\
\text { than } \\
7\end{array}$ & 2,97 & 2,02 & 1,92 & 2,70 \\
\hline
\end{tabular}

Source: Author's analysis of survey
Given the recommendations and suggestions of tourists about the improvement of the package tours in Dubrovnik, tourists who came in the organization of a travel agency are of the opinion that the key activities important to survive and furthermore development of travel intermediary businesses are related to: a) additional facilities (spas, sports centres) $(18 \%)$; b) diverse offer of food drinks in restaurants $(15 \%)$; c) quality of accommodation $(9 \%)$; c) better information $(4 \%)$; and d) more tourist events, better cultural contents (27\%). Respondents also mentioned better organization, the coordination and compliance at the level of service providers (3\%), better service in general $(3 \%)$, and cleanliness of beaches (1\%) influence on improving.

Considering the characteristics of their stay, tourists who come by car in the largest share (7\%) state better information as an important factor in improving the quality of the tourist package tours in Dubrovnik. Regardless of whether tourists have been to Dubrovnik once or more than once, the most important recommendation is the quality of basic services in destination as food, drinks and accommodation. Tourists who travel alone in the largest share $(31 \%)$ point out as the main recommendation for improving.

3.2.7. Critical analysis of the impact of structural changes in the tourism market on the specialization of the business of travel intermediaries in a tourist destination

In the conditions of mass tourism, it is important to analyze the impact of structural changes in the organization and operation of all subjects of the tourist offer. This impact consequently results in new trends in tourism and has great significance for the future of agency business.

To prove hypothesis $(\mathrm{H})$ which claims Structural changes in the tourism market impact on the specialization of business of travel intermediaries, the method of multiple logistic regression was used. The dependent variable The specialization of the program of travel agency is defined as a binary variable that takes on two possible values related to the programs of specialization in accordance of tourists' requests. Respondents were asked to rate the extent to which a travel agency has specialized programs according to their needs

("Travel agency has programs specialized according to my needs" $=1$; "Travel agency does not have programs specialized according to my needs" $=0$ ). 
From all the respondents (248) who arrived in Dubrovnik using travel agency, the majority of respondents $(76 \%)$ answered that programs of travel agencies are specialized according to their wishes and expectations, while (24\%) of respondents answered that travel agencies does not have a specialized program according to their wishes.

Independent variables: The impact of structural changes on the specialization of programs of travel agencies

Structural changes are measured through the following variables:

a) direction of specialization in relation to the segments,

b) vertical integrations,

c) characteristics of the arrangement (the whole arrangement versus partially integrated services).

The direction of specialization was measured through the importance of certain facilities (activities) for market segments, tourists. Respondents assessed whether the following programs were important for the selection of arrangements: health and recreation program, sailing, adventure sports and cultural events.

Vertical integrations are measured in responds of tourists' considering the way of booking of services used. Respondents are asked to indicate about the way of booking: used way of their organization of travel (via tour operators, via travel agencies or via Internet).

Characteristics of the package tours are analyzed through the way of creation of package tours, depending on the mode of arrival, based on the use of the means of transport. Respondents are asked to indicate the extent to which the facilities, activities they use during their stay are included in the package tours

\section{Results of multiple logistic regression}

Table 4. shows the results of multiple logistic regression.
Table 4 Basic results of the multiple logistic regressions (dependent variable: the specialization of travel agency; "exists" or "no"; independent variables: structural changes on the tourism market)

\begin{tabular}{|c|c|c|c|c|c|}
\hline $\begin{array}{l}\text { Structural } \\
\text { changes }\end{array}$ & $\begin{array}{l}\text { Modaliti } \\
\text { es of } \\
\text { structura } \\
1 \\
\text { changes }\end{array}$ & $\begin{array}{l}\text { B (The } \\
\text { coeffici } \\
\text { ent of } \\
\text { logistic } \\
\text { regressi } \\
\text { on) }\end{array}$ & $\begin{array}{l}\text { Wal } \\
\text { d } \\
\text { test }\end{array}$ & $\begin{array}{l}\mathrm{D} \\
\mathrm{F}\end{array}$ & $\begin{array}{l}\text { p- } \\
\text { value } \\
\text { of } \\
\text { Wald } \\
\text { test }\end{array}$ \\
\hline \multirow{4}{*}{$\begin{array}{l}\text { Direction } \\
\text { of } \\
\text { specializati } \\
\text { on in } \\
\text { accordance } \\
\text { with } \\
\text { market } \\
\text { segments }\end{array}$} & $\begin{array}{l}\text { Health } \\
\text { and } \\
\text { recreatio } \\
\text { nal } \\
\text { program }\end{array}$ & 4,143 & $\begin{array}{l}8,66 \\
8\end{array}$ & 1 & $\begin{array}{l}0,003 * \\
* *\end{array}$ \\
\hline & Sailing & $-2,949$ & $\begin{array}{l}2,36 \\
2\end{array}$ & 1 & 0,124 \\
\hline & $\begin{array}{l}\text { Adventu } \\
\text { re sports } \\
\text { and } \\
\text { rafting }\end{array}$ & 20,326 & $\begin{array}{l}0,00 \\
0\end{array}$ & 1 & 0,999 \\
\hline & $\begin{array}{l}\text { Cultural } \\
\text { events }\end{array}$ & $-20,497$ & $\begin{array}{l}0,00 \\
0\end{array}$ & 1 & 0,999 \\
\hline \multirow[t]{3}{*}{$\begin{array}{l}\text { Vertical } \\
\text { integration } \\
\mathrm{s}\end{array}$} & $\begin{array}{l}\text { Booking } \\
\text { via tour } \\
\text { operator } \\
\mathrm{s}\end{array}$ & 1,861 & $\begin{array}{l}0,11 \\
0\end{array}$ & 1 & 0,740 \\
\hline & $\begin{array}{l}\text { Booking } \\
\text { via } \\
\text { travel } \\
\text { agencies }\end{array}$ & 1,058 & $\begin{array}{l}15,1 \\
84\end{array}$ & 1 & $\begin{array}{l}0,000 * \\
* *\end{array}$ \\
\hline & $\begin{array}{l}\text { Booking } \\
\text { via } \\
\text { Internet }\end{array}$ & 0,809 & $\begin{array}{l}4,09 \\
9\end{array}$ & 1 & $\begin{array}{l}0,043 * \\
*\end{array}$ \\
\hline \multirow[t]{2}{*}{$\begin{array}{l}\text { Characteris } \\
\text { tics of } \\
\text { package } \\
\text { tours }\end{array}$} & $\begin{array}{l}\text { Mode of } \\
\text { arrival } \\
\text { in } \\
\text { relation } \\
\text { to used } \\
\text { means } \\
\text { of } \\
\text { transport }\end{array}$ & 0,646 & $\begin{array}{l}1,27 \\
6\end{array}$ & 1 & 0,259 \\
\hline & $\begin{array}{l}\text { Integrati } \\
\text { on of } \\
\text { activities } \\
\text { in the } \\
\text { package } \\
\text { tours }\end{array}$ & 2,134 & $\begin{array}{l}0,00 \\
0\end{array}$ & 1 & 0,987 \\
\hline Constant & & $-6,488$ & $\begin{array}{l}0,00 \\
0\end{array}$ & 1 & 1,000 \\
\hline $\begin{array}{l}\text { Nagelkerk } \\
\text { e R Square }\end{array}$ & \multicolumn{5}{|l|}{0,468} \\
\hline
\end{tabular}

The results with a view to the aspect of vertical integration seem to be very significance, 
especially if tourists have booked a stay through a travel agency.

The of variations (indicator Nagelkerke R Square $=0.225)$ of the dependent variable "the specialization of the program of travel agency" under the influence of socio-of economic changes, described in the selected independent variables of social changes: religious reasons, adventures, health reasons, new experiences, cultural reasons The model explains total $46,8 \%$ of variations (Nagelkerke $R$ Square) in specialization of programs of travel agencies in structural changes. The impact of independent variables (structural changes) on the dependent variable (specialization of travel intermediaries) is as follows:

Health/recreational program - an independent variable statistically significantly affects on a binary dependent variable Y -Specialization of the program of travel agency -at the $1 \%$ level of significance $($ Wald test size $=8,668, \mathrm{p}$-value $=$ 0,003) with a positive correlation (estimated logistic regression coefficient is positive and it is 4,143). Other independet variables ( sailing, adventure sports and rafting, culural events) which measure the direction of market segmentation statistically significantly do not affect on a binary dependent variable $\mathrm{Y}$-Specialization of the program of travel agency. For sailing pvalue $=0,124$ (Wald test size $=2,362)$. For adventure sports and rafting $\mathrm{p}$-value $=0,999$ (Wald test size $=0,000)$; for cultural events $p$-value $=0,999$ (Wald test size $=0,000$ ).

The booking via travel agencies statistically significantly increases the likelihood that the client will choose the specialized program of the travel agency -at the $1 \%$ level of significance (Waldova test size $=15,184 ; p$-valuet $=0,000)$, while the booking via Internet statistically significantly increases the likelihood that the client will choose the specialized program (package tour) at the $5 \%$ level of significance (Waldova test size $=4,099 ; p$ value $=0,043$ ). The booking via tour operators statistically significantly do not increases the likelihood that the client will choose the specialized package tour. (Waldova test size $=0,110 ; p$-value $=0,740)$.

The characteristics of package tours (mode of arrival in relation to used means of transport, integration of various activities in the package tour ) are not statistically significantly related to the specialization of the business of travel agencies.

\section{Conclusion}

The world economy is showing intense changes, so it is increasingly difficult to penetrate a competitive market without business cooperation and strong connections on a complementary basis with the foundation of regional economic integration. Competitiveness is no longer a local issue, so most companies operate in conditions of global competitiveness.Globalization is mostly possible due to technological changes. Information and communication technology (ICT) has a strong impact on tourism trends by creating, distributing and informing about tourism products. Technical and technological changes affect all aspects of human activity and life, including tourism as a phenomenon that very quickly reflects changes in society. The Internet and new technologies arising from its application, generate high-speed of new forms of communication, open new opportunities, and tourism intermediaries quickly learn about the needs of clients, their motives, as well as ways to make decisions about tourist travel. Competitiveness is no longer a local issue, so most companies operate in a global competitive environment. The world economy is showing intense changes, so it is increasingly difficult to penetrate to the competitive market without business cooperation and strong connections on a complementary basis on the regional economic integration. There is ample evidence that globalization in the tourism market events itself at the same time acts as a catalyst for further strong structural changes in the same market. Globalization is largely possible due to technological changes, (ICT)has a strong impact on tourism trends by creating, distributing and providing information about tourism products.. Technnical and technological changes affect all aspects of human activity and life, including tourism as a phenomenon that very quickly reflects changes in society. The Internet and new technologies that result from its application manage costs by time savings through the emerged advantages from both travel market poles. Generating high-speed of new forms of communication, opening new opportunities, travel intermediaries more quickly learn about needs of clients, their motives, as well as ways to make decisions about their travel. There is an ample evidence that globalization is manifested through the quantitative increase in the tourism demand market, but at the same time acts as a catalyst for further strong structural changes in the same market, tourism market. The impact of structural changes in the tourism market on the specialization of the business of travel intermediaries was analyzed, thus contributing to an important area of 
specialization in tourism system. The specialization of travel intermediaries is an important lever to increase the competitiveness of both these economic entities and the entire tourist system. In order to examine the impact of structural changes in the tourism market on the further specialization of travel agencies, the direction of specialization of product programs according to market requests, level of vertical integrations, and finally the area of characteristics of package tours considering the level the integration of activities into the product, and the modality used means of transport, as independent variables were taken into account. Structural changes in the tourism market have been identified while the powerful effects of changes on the specialization of the business of tourism intermediaries have been observed. The multiple logistic regression model shows the following:: (1) Attitudes of tourits about importance of health/recreational program statistically significantly affects on specialization of the program of travel agencies at the $1 \%$ level of significance $($ Wald test size $=8,668$, p-value $=$ $0,003)$; (2) Importance of the other activities as sailing, adventure sports and rafting, culural events which measure the direction of market segmentation statistically significantly do not affect on specialization of programs of travel agencies ; (3) If tourists book services via travel agencies statistically significantly increases the likelihood that the clients choose the specialized program of the travel agency -at the $1 \%$ level of significance ( $p$ valuet $=0,000)$, (4) The booking via Internet statistically significantly increases the likelihood of choosing the specialized program of the package tour at the $5 \%$ level of significance ( $p$-value $=0,043) ;(5)$ The booking via tour operators is not statistically significantly related to the specialization of the business of travel agencies;.(6) The characteristics of package tours (mode of arrival in relation to used means of transport, integration of various activities in the package tour ) are not statistically significantly related to the specialization of the business of travel agencies.These findings prove hypothesis $(\mathrm{H})$ of this paper. It can be concluded that the scientific contribution was achieved by measuring changes in tourism, by examining the role of new technologies in tourism and examining the impact of structural changes in the tourism market.Findings point out the strongest impacts of structural changes, observed and the identified in the field of: a) habits and behaviour related to communication and using specific way of booking; b) in the field of the preference for specialisation of program of products (health/recreational program) and the assessment of the level of specialisation of activities used.
The results suggest the need for constant adaptation to the requirements of tourists. The reason for adjustments can be found in a reasonable way of doing business based on internal and external changes in the environment These changes include lifestyle changes, specific attitudes towards: the leisure, the managing of free time using new technologies, the direction of travel, specific interests related to travel reasons, the way of booking services related to stay, and the role of travel intermediaries. Due to these changes, tourists are looking for more complex products of intermediaries that suit their needs. At the same time, tourists are better informed and they appreciate faster information.

This could influence on an additional pressure in the competitive travel market developing and transforming the channels of travel intermediaries for the efficient product placement. Modalities of structural changes will certainly affect the business of travel intermediaries, obvious as an effort to achieve an efficiency of special business areas (specialization) and functions for the quantification of new trends.

The direction of future reserarch in this area will be in core of differences beteween two opposite market poles, in mediating, finding the compromises and measuring the intesity of changes that test the adoptible, the competitive way of production and communication, so far that could even transform the travel intermediary itself.

\section{References:}

[1]Wartini-Twardowska, J., Twardowski, Z., (2019). Searching for synergy from a combination of heterogeneous business models: measurement and assessment from the Polish software industry. Heliyon Vol.5, No. 7, e01970

[2] Yu-hsin Chang (2020). Identifying positions and roles of travel agencies based on relationship redundancy in a package tour network, Heliyon Vol. 6 No.1, e03227

https://www.cell.com/heliyon/fulltext/S24058440( 20)30072-4

[3] Dupeyras, A.; MacCallum, N. (2013). Indicators for Measuring Competitiveness in Tourism-A Guideance Document. OECD , Tour.

Pap.

[4]Teodorescu, N. , Stăncioiu A.F, .Sidonia Ravar, A, Botos, A. Creativity and innovation - Sources of competitive advantage in the value chain of tourism enterprises, Theoretical and Applied Economics, Volume XXII No. 1(602), 
pp. $35-48$

[5] Bellini, N.; Grillo, F.; Lazzeri, G.; Pasquinelli, C. (2017). Tourism and regional economic resilience from a policyperspective: Lessons from smart specialization strategies in Europe. Eur. Plan. Stud. , 25, 140-153.

[6] Del Vecchio, P.; Passiante, G. .( 2017), Is tourism a driver for smart specialization? Evidence from Apulia, an Italian region with a tourism vocation. J. Destin. Mark. Manag, Vol.6, 163-165.

[7] Romão, J.; Neuts, B. (2017).Territorial capital, smart tourism specialization and sustainable regional development:Experiences from Europe. Habitat Int. Vol- 68, 64-74.

[8] European Comission (2019). Education and training monitor(2019). https://ec.europa.eu/education/sites/education/ files/document-library-docs/et-monitor-report2019-croatia en.pdf

[9].Bonn, M. A., Furr, H. L., Susskind, A. M. (1998). Using the Internet as a pleasure travel planning tool: An examination of the sociodemographic and behavioral characteristics among Internet users and nonusers. Journal of Hospitality \& Tourism Research, Vol.22, No. 3, pp. 303-317.

[10].Beldona, S.,Morrison, A. M, O’Leary, J. (2005), Online shopping motivations and pleasure travel products: a correspondence analysis, Tourism Management, Vol. 26,Nno. 4, pp. 561-570.

[11].Eurostat (2019). Tourism Industries Employment. Retrieved 20.2.2018 from https://ec.europa.eu/eurostat/statisticsexplained/index.php?title=Tourism_industries -employment\#Data sources and availability

[12] Eurostat (2018). Annual detailed enterprise statistics for services (NACE Rev. $2 \mathrm{H}-\mathrm{N}$ and S95).

http://appsso.eurostat.ec.europa.eu/nui/show.do?da taset=sbs_na_1ase_r2\&lang=en

[13] Ghorbani, A., Danaei, A., Zargar, S.M., Hematian, H., (2019). Designing of smart tourism organization (STO) for tourism management: a case study of tourism organizations of South Khorasan province, Iran. Heliyon Vol. 5, No. 6, e01850

[14] Abrahamsen, M.H., Henneberg, S.C., Naude, P.,(2012).Using actors' perceptions of network roles and positions to understand network dynamics. Ind. Mark. Manag. Vol. 41, No. 2, pp. 259-269.

[15] Haberli Junior, C., Oliveira, T., Yanaze, M.,
Spers, E.E., (2019). Performance, farmer perception, and the routinisation (RO) moderation on ERP post-implementation. Heliyon, Vol 5, No.6, , e01784.

[16] Boonstra, T.W., Larsen, E., Christensen, M.H., (2015). Mapping dynamic social networks inreal life using participants' own smartphones. Heliyon, Vol 1, No.3,e00037.

[17] Lozada, N., Arias-P erez, J., Perdomo-Charry, G., (2019). .Big data analytics capability and co-innovation: an empirical study. Heliyon Vol. 5, No.10, ,e02541.

[18]Foray, D. (2015). Smart Specialisation Opportunities and Challenges for Regional Innovation Policy;

[19] Šošić, I. (2006). Primijenjena statistika., Drugo izdanje, Školska knjiga, Zagreb, str. 489.

[20]Eurobarometer (2019). Preferences of Europeans towreds Tourism https://data.europa.eu/euodp/en/data/dataset/S 2065_432_ENG

\section{Creative Commons Attribution}

License 4.0 (Attribution 4.0

International , CC BY 4.0)

This article is published under the terms of the Creative Commons Attribution License 4.0 https://creativecommons.org/licenses/by/4.0/deed. en_US 